\title{
EL IMAGINARIO COLECTIVO Y EL TEATRO YUYACHKANI
}

Mabel Muñoz Matiu

Universidad Ricardo Palma

\section{RESUMEN}

Es el estudio de la relación entre el imaginario colectivo y el teatro Yuyachkani. Teatro que es producto de un trabajo colectivo e independiente y que expresa la diversidad cultural peruana.

PALABRAS CLAVE

Imaginario colectivo / Teatro / Máscaras / Mitos / Ceremonial.

\begin{abstract}
It is the study of the connection between the collective imagination and the Yuyachskani theatre. The theatre is the result of a collective independent work which expresses the Peruvian cultural diversity.
\end{abstract}

KEYWORDS

Collective imagination / Theatre / Masks / Myths / Ceremonial. 
Si el teatro ha sido creado para permitir que nuestras represiones cobren vida, esa especie de atroz poesía expresada en actos extraños que alteran los hechos de la vida demuestra que la intensidad de la vida sigue intacta, y que bastaría con dirigirla mejor.

(Artaud, 2005. p. 9.)

El grupo cultural Yuyachkani nació en el año 1971. Es un teatro colectivo e independiente. Sus obras están dirigidas y relacionadas con la sociedad y la diversidad cultural peruana.

Silvio D’Amico en Historia del Teatro Universal, define al teatro como "La comunión de un público con un espectáculo viviente.", y dice que las expresiones teatrales son de naturaleza colectiva.

El teatro es una expresión artística que, quizá, como ninguna otra es propia de una colectividad participante tal como un ritual religioso.

En el caso que nos ocupa, el caso del Teatro Yuyachkani, lo elegimos porque consideramos que en sus obras logra como ningún otro expresar el imaginario colectivo de los pueblos que conforman el Perú en toda su diversidad. Sus obras son producto de un trabajo colectivo del director, actores, artistas que confeccionan las máscaras, los trajes y todo lo que se necesita para montar el espectáculo.

El presente estudio está basado en su mayor parte en el libro Raíces y semillas. Maestros y caminos del teatro en América Latina, escrito por Miguel Rubio, director del teatro Yuyachkani. La mayor parte de las citas provendrán de este texto que lo consideramos muy valioso y que nos permite valorar el trabajo colectivo de este grupo.

En el trabajo de este grupo, entregado por entero al quehacer teatral, y que vive en el teatro y para el teatro, destaca su sensibilidad para captar, a través de las investigaciones que realiza la esencia de los diferentes pueblos que habitan en espacios tan diversos como son los del Perú. Esta particularidad la reconoce su director cuando dice: "Me siento un testigo privilegiado por haber vivido de cerca momentos en los que no había ninguna duda sobre el tema y donde se suscribía con orgullo la vitalidad del teatro latinoamericano"(Rubio, 2011, p. 12), y más adelante agrega: "El grupo fue la cédula madre en que nos organizamos para gestar esa 
nueva teatralidad que reclamábamos a voz en cuello y que debía marchar acorde con los tiempos que se vivían, donde predominaba un sentimiento colectivo" (Rubio, 2011, p. 14).

Páginas más adelante, Rubio dice: "Si tomáramos como punto de partida la mitad del siglo pasado, veríamos un movimiento en proceso, un teatro que se lanza a inventarse, a reconocer sus particularidades como resultado de una grande y rica diversidad cultural y, al mismo tiempo, veríamos nuevos sectores sociales tradicionalmente deprimidos sacando la cabeza como público, como hacedor y copartícipe primordial." (Rubio, 2011, p. 15).

En el capítulo llamado Máscaras, memorias y Orígenes del teatro en el Perú, del libro ya citado, el autor se detiene a resaltar el trabajo realizado por Arturo Jiménez Borja y explica que mirando esa colección de máscaras, podría preguntarse “¿Desde cuándo existe teatro en el Perú? $\mathrm{Y}$ dice que esta pregunta era fundamental en su vida como hombre de teatro y que a partir de ver la colección de máscaras de Arturo Jiménez Borja sintió que le fue revelado un universo desconocido, porque mirando estas máscaras muy antiguas del Perú descubrió que debía replantarse la noción recibida en la escuela donde se le enseñó que el teatro era un género literario que había llegado a estas tierras con la conquista, y agrega: "Así, pude encontrarme con inusitados personajes como kusillos, diablos, aukis, loros, venados, osos, gavilanes, etc., cada uno de ellos con una historia por develar...". Y continua diciendo: "A lo largo de sus innumerables viajes por el Perú, Arturo Jiménez Borja logró reunir una importante colección de aproximadamente 250 máscaras, pertenecientes a danzantes enmascarados de fiestas muy diversas de Huánuco, Huancavelica, Cusco, Puno, Cajamarca, Lima e Iquitos" (Rubio, 2011, pp. 215-216).

En el libro se nos informa que Jiménez Borja en su infancia vivió en Bolivia y ahí nació su fascinación no sólo por las máscaras, sino también por los trajes, tocados y accesorios que se usan "En las fiestas tradicionales junto con las polleras, plumas, mantas de colores y capas finamente bordadas" (Rubio, 2011, p. 216).

Este es un teatro diferente, porque supera la existencia de un texto previamente escrito que surge del juego y los roles distintos que se intercambian y donde "la comunidad juega y simboliza". 
Son las máscaras que expresan el vínculo con la memoria ancestral que además permite descubrir la semejanza que tienen con las obras de las culturas Sechín, Chavín y Tiahuanaco. Son las figuras que vemos en las máscaras que pertenecen a los diablos danzantes de la Diablada puneña "[...] en cuyo rostro recorren luciérnagas, sapos, culebras y con grandes colmillos que salen de su boca." (Rubio, 2011, p. 216).

Motivado ante la visión de estas máscaras comenzó la búsqueda para descubrir " $[\ldots]$ a ese universo de identidades, personajes, secretos y símbolos, que llevan consigo guardadas en la memoria de sus formas y situaciones de representación." (Rubio, 2011, p. 217).

Por nuestra parte, éste es el valor que reconocemos en el trabajo de Yuyaschkani: la recreación del escenario de estas manifestaciones propias de los pueblos que conforman el Perú profundo y que reconoce que hoy este mundo expresa no sólo lo que fue el arte indígena, sino lo que es hoy producto del contacto con el mundo hispano, al cual se sumó, también, lo africano. Este reconocimiento se denota cuando señala:

Durante la conquista y el coloniaje, a la exclusión de los indígenas -cuya condición de seres humanos, incluso, fue puestas en duda por la ideología oficial-, correspondió la exclusión de prácticas artísticas y culturales. Estos últimos procesos no se pueden considerar concluidos aun hoy. En la misión colonial, aquello que no pudo ser erradicado fue incorporado para interiorizar los valores del catolicismo usando para ello los elementos de representación presentes en la danza, la música y la imagen, los que posteriormente van a ser asimilados en los grandes despliegues festivos, iniciándose así los niveles de mezcla y sincretismo con los cuales convivimos hoy y los que sustentan el encuentro de elementos prehispánicos y cristianos en una conjunción de ritos de diversa procedencia. Sensibilizarnos sobre cómo opera este mecanismo sincrético es fundamental para entender la mezcla y la "hibridación" de procesos culturales en constante movimiento. (Rubio, 2011, p. 217).

Para Peter Brook, existen dos elementos, el rito y el ceremonial como valores originarios del teatro. El teatro sagrado trasciende lo verbal y establece una identificación con la naturaleza, inspirado en los sonidos de la misma; más que la expresión verbal, busca y logra penetrar en el mundo interior independiente de la lógica y la sintaxis y es ahí donde se encuentra el imaginario colectivo. La máscara para Brook: "Es la imagen de la naturaleza esencial" (Foix \& Brook, 2008, p. 146). 
Lo que logra Yuyaschkani con sus puestas, es regresar a lo primitivo, al desborde, al origen, al caos, lo que Brook llama "La cultura de los eslabones" y éste es el teatro que logra expresar la separación entre teatro y representación ceremonial, lo cual es difícil determinar. Al respecto, Rubio señala: "Por eso nos parece justo afirmar una teatralidad compleja que tenga que ver con reconocernos en una identidad inclusiva" (Rubio, 2011, p. 18), $\mathrm{y}$, en la misma página, el autor dice que hombres de teatro como Antonin Artaud, Peter Brook y Eugenio Barba "[...] dirigieron una atenta mirada hacia lo sagrado, lo ritual y lo antropológico... Esta mirada se nos devuelve como un espejo en cuyo reflejo todavía no nos hemos confrontado de manera suficiente con ese caudaloso imaginario escénico que habita entre nosotros desde los origines de nuestra civilización." (Rubio, 2011, p. 18).

Quizá la particularidad de un teatro que logra exponer el imaginario colectivo es el que no interpreta un texto, sino que crea un contexto (Barba \& Savarese, 2012, p. 254).

Tener la capacidad de absorber la esencia de ceremonias rituales, de fiestas populares y recrearlas en la representación, exige de una gran sensibilidad, pero es sobre todo producto de la observación y de un fuerte trabajo que requiere de años de experiencia tanto del director como de sus actores.

En el capítulo titulado El verdadero Texto Teatral es el texto del espectáculo, Miguel Rubio desarrolla una conversación con Enrique Buenaventura, director de teatro colombiano. En este diálogo, Rubio plantea que las danzas, bailes y canciones que se observa en las comunidades indígenas existen importantes elementos de teatralidad que son fuentes básicas para alimentar el teatro nacional, sin embargo considera que no es siempre teatro y aquí Buenaventura responde al respecto: "Es evidente que este producto funciona en su contexto, en sus condiciones, y que es un producto que ha tenido que ser protegido de alguna manera contra las influencias externas; por lo tanto, de alguna manera es un producto arcaico. Todo esto hay que estudiarlo en cada condición, en cada contexto, puesto que este aspecto de trabajar con los materiales populares llamados folklóricos, con los materiales indígenas o con los materiales negros es un aspecto muy difícil, muy complejo. Puede hacerse cosas muy superficiales, puede hacerse meros trasplantes mecánicos, meras imitaciones torpes, como puede hacerse un trabajo extraordinariamente valioso si se sabe cómo trabajar con estos materiales." (Rubio, 2011, 47). Y esto último es lo que hace el grupo Yuyachkani, saber cómo trabajar con esos materiales. 
En otro de los capítulos del libro que venimos citando: Las manos que danzan, pero que además "han aprendido a pensar", Miguel Rubio nos presenta a Edmundo Torres, el maestro que hace las máscaras que usan los actores de Yuyachkani y se nos presenta a un artista cuyo "ser creador fluye porque (Torres) se considera parte de una memoria compartida y de una tradición que orgánicamente viaja con él y que tiene muy presente por esa fuerte raíz que lo vincula al lugar de donde proviene: la meseta altiplánica del Collao, en Puno, Perú” (Rubio, 2011, p. 100).

De otro lado, Rubio nos cuenta como realizó Torres su primera máscara cuando estaba en la escuela y tenía que bailar como diablo. "Diablo" así lo denominaron los españoles, pero no podemos saber hoy cómo lo denominaban los indígenas en el pasado, ellos fueron los que lo crearon y Rubio dice: "Es un icono que se remonta a tiempos inmemoriales" y que es la representación de deidades tutelares. Es innegable que este símbolo representa seres que encontramos en obras arqueológicas que dan testimonios de antiguas culturas peruanas. La máscara del diablo tiene cachos enormes, orejas de sapo y el rostro poblado de reptiles, dientes de fluidos espejos y colmillos que salen de la boca. Viendo esta máscara se nos presenta la imagen de la estela Raimondi, así como también de las cabezas clavas, de los templos que se encuentran dispersos en todo el Perú. El conocimiento de ese pasado que se sigue incrementando con nuevos descubrimientos arqueológicos.

El capítulo Las manos que danzan, tiene un subtítulo Las máscaras del mundo en el teatro Yuyachkani, Rubio nos cuenta el trabajo de Torres con los actores cuando se preparaba con los músicos ambulantes, la obra más conocida y representada del Teatro Yuyachkani y que hoy, en el año 2013, ha cumplido 30 años de presentaciones. Según nos cuenta Rubio, la obra tuvo dos referentes, los saltimbanquis: de Enriques y Bardotti, y el cuento alemán Los músicos de Bremen de los hermanos Grimm.

Los Músicos Ambulantes transcurre durante un viaje a Lima, que realizan cuatro animales que representan diferentes regiones del Perú, cuyo objetivo era realizar su sueño el de ser artistas, músicos y cantantes. Cada uno de estos animales son la expresión de una región del Perú: el burro es el sur andino, el perro es del norte, la gallina negra viene del sur de la costa y la gata de la selva. Al conocerse en el camino surge la idea de formar un conjunto musical. Es en este punto cuando el director del grupo nos explica que

El trabajo corporal de los actores contiene información de su carácter animal, humano, regional, de género y edad. Edmundo Torres fue 
construyendo las máscaras en grandes discusiones con los actores, sobre cómo cada quien imaginaba su personaje y las propuestas varias - que él fue construyendo pacientemente para cada rostro de cada actor... Los personajes deberían llevar máscaras todo el tiempo con los problemas técnicos que fueron apareciendo en el camino, como que las máscaras se iban deshaciendo con el sudor porque los personajes bailan, cantan, tocan instrumentos, hablan, etc., y en el teatro, cuando los personajes hablan usan medias máscaras para que la emisión de la voz salga nítida y se pueda escuchar claramente lo que se dice. Por otro lado, la boca y la parte inferior del rostro de quien la porta completa la fisionomía de la máscara, haciendo un trazo continuo cerrando el círculo y formando una unidad con ella. (Rubio, 2011, pp. 105-106).

Aquí Rubio señala que la técnica mejor desarrollada fue la de la Comedia dell'Arte. Nuevamente recurrimos a la lectura de Silvio D'Amico quién explica que la "Comedia dell'Arte", también denominada en su época Comedia Bufonesca o Comedia Histriónica, surgió en Italia como una organización nueva de "... actores que necesitaron de un adiestramiento técnico, mímico, vocal y acrobático.” (D’Amico, 1954, p. 96).

Más tarde este tipo de representación se expandió en gran parte de Europa durante los siglos XVII y XVIII. Es el teatro que abandona el texto como centro de la obra teatral y considera al actor el hacedor de la obra prescindiendo en gran medida del texto para resaltar el baile y el canto. Rubio en un momento de su libro dice: "Se sabe que en el antiguo Perú bailar y cantar tenía una palabra unificadora: Taqui, que quiere decir "baile". Así ambas actividades o expresiones artísticas estaban vinculadas una a la otra. De esta manera, se sabe que no había baile, que no incluyera un canto o cantos que los acompañasen y viceversa. No deja de sorprendernos cómo en muchas de estas celebraciones de la vida y de la muerte, que hasta ahora vemos vivas y renovadas en todo el Perú, está presente un antiguo origen. Para asistir a alguna, Jiménez Borja vio que no había que ir muy lejos de Lima; es el caso de las fiestas que, con motivo de la limpia de la acequia, se realizan en San Pedro de Casta, donde se canta y se baila en medio de las faenas comunales" (Rubio, 2011, pp. 221-222).

D'Amico, por su parte, subraya la importancia de la aparición de las máscaras en la Comedia dell'Arte y de la transferencia que se realiza entre los actores y las máscaras que de forma constante las usan hasta confundir al personaje que representa cada una de las máscaras típicas de 
esta comedia con el actor donde el público indistintamente llama a éste por su nombre o a veces lo reconoce mas con el nombre del personaje que representa la máscara que usa.

Más adelante, D’Amico señala que

...la mímica del actor italiano se expresaba muy a menudo no con el juego fisionómico, sino, como por otra parte había ocurrido también en la antigüedad, y todavía ocurre en Oriente, con el empleo de toda la figura, de todo el cuerpo.

Es necesario tener presente, especialmente por lo que respecta a la comicidad, otro elemento: el elemento acrobático. La comedia dell'arte, espectáculo en su mayor parte visual, adiestraba a sus artistas no sólo en la gimnasia, con un propósito evidente de hacerles adquirir soltura y prestancia física, sino también en la acrobacia. Contorsiones y piruetas, volteretas y saltos mortales, eran su especialidad... (D'Amico, 1954. pp. 136-137).

Y más adelante, D'Amico agrega: "Y no es necesario decir que a estas virtudes acrobáticas los cómicos italianos agregaban la de ser músicos y bailarines; la comedia dell'arte floreció a menudo entre danzas y canciones." (D'Amico, 1954, p. 138).

Y también hay que mencionar lo que nos informa el mismo autor, que: "En los tiempos de la Reforma Protestante y de la Contrarreforma Católica, los cómicos italianos fueron ásperamente combatidos por los maestros de la vida religiosa y por las autoridades eclesiásticas; éstas trataron con frecuencia de inducir, a veces con éxito, a las autoridades civiles a adoptar medidas restrictivas. Y explica la marca infamante con que idealmente se volvió a distinguir a los actores" (D'Amico, 1954, p. 146).

Por algo el símbolo del teatro son las dos máscaras que representan la tragedia y la comedia. El teatro Yuyachkani siempre le dio un lugar privilegiado a las máscaras en sus puestas en escena y no es por casualidad que Miguel Rubio en la obra Raíces y Semillas valora el gran aporte realizado por el antropólogo Arturo Jiménez Borja en Máscaras, memoria y orígenes del teatro del Perú, último capítulo de Raíces y Semillas. Es Jiménez Borja quien a través de sus investigaciones reconoce: "Explícitamente que las máscaras no han sido hechas para estar colgadas en una pared, y es cierto. Entre la máscara, como objeto determinado con forma y color, y el cuerpo del danzante que la lleva, se produce un intercambio de identidades de cuya 
fusión aparece otra entidad. El ejecutante enmascarado forma parte de un conjunto, deja de ser quien es, no se le debe reconocer, es una pieza más del ensamblaje. Por ello, es necesario entender además que el enmascaramiento no implica sólo el rostro, sino que supone un cuerpo transformado, un traje, un código de comportamiento, una historia escrita en el vestido, en los accesorios y en los pasos de sus danzantes enmascarados. (Rubio, 2011, p. 217).

También es necesario presentar una de las últimas publicaciones de Yuyachkani, junio del 2013, de la serie "Memoria que danza" titulada Guerrilla en Paucartambo, ilustrada por Jesús Cossio Guevara con la idea original y guión de Miguel Rubio Zapata.

\section{¿Qué es lo que se presenta en esta obra?}

La celebración en honor a la Virgen del Carmen, "una de las fiestas más importantes del sur andino". Nos interesa en esta historia resaltar algo que dice Rubio: "Los personajes medulares que se confrontan (en la Guerrilla) pertenecen a dos grupos de danzantes: los q'hapac qolla y los q'hapac ch'unchu, alrededor de los cuales se construye el perfil ritual y mitológico del evento. Los saqras también tienen un rol protagónico: se encargan de llevar a los muertos en su carro de fuego. Estas tres danzas marcan las tensiones de la fiesta, son actores de un enfrentamiento de alto valor simbólico por la carga histórica que subyace en el argumento, que es conocido por el pueblo y que se repite invariablemente todos los años como un ritual teatral." (Rubio, 2013, p. 5).

Enlazado con todo lo que venimos analizando, consideramos que vale en este momento citar un trabajo de Peter Brook titulado La puerta abierta:

Cuando visité Irán por primera vez en 1970, presencié una poderosa forma de teatro conocida como Ta'azieh. Nuestro pequeño grupo de amigos había recorrido un largo camino a través de Irán [...] para acudir a una inverosímil cita con una representación teatral. Súbitamente nos encontramos con el muro pardo que rodeaba la población donde doscientos de sus habitantes formaban un círculo cerca de un árbol. De pie o sentados bajo el cielo abrazador, formaban un anillo de humanidad tan completo que nosotros, los cinco extranjeros, fuimos completamente absorbidos en su unidad. Había hombres y mujeres con la vestimenta tradicional [...] los aldeanos estaban expectantes porque sabían hasta el último detalle 
de lo que iba a ocurrir y nosotros, que nada sabíamos, éramos un tipo de público perfecto. Todo lo que nos habían contado era que el Ta'azieh es la forma islámica de los misterios cristianos, que había muchas de tales obras y que trataban del martirio de los doce primeros imames discípulos del profeta [...].

El músico que se sentaba bajo el árbol inició un insistente ritmo con su tambor y un aldeano se adelantó al centro del círculo. Calzaba botas de goma y tenía aire de arrojo. Alrededor de los hombros llevaba una pieza de tela de un verde vivo, el color sagrado, el color de la tierra fértil, que demostraba, según nos dijeron, que se trataba de un hombre santo. Empezó a cantar una larga frase melódica compuesta de unas cuantas notas con una estructura que se repetía y se repetía, con palabras que no comprendíamos, pero cuyo significado se aclaró al instante gracias a un sonido que procedía de las entrañas del cantante. Su emoción no le pertenecía. Era como si escucháramos la voz de su padre, y del de su padre de su padre y de todos sus antepasados. Estaba ahí de pie, con las piernas separadas, poderoso, totalmente convencido de su función, y era la encarnación de esa figura que en nuestro teatro es siempre la más esquiva: el héroe [...] otro personaje, esta vez envuelto en una tela roja entró en el círculo. La tensión fue inmediata; el malo había llegado. No cantó, no tenía derecho a la melodía, se limitó a declamar en un tono fuerte y áspero, y el drama se puso en marcha [...] el argumento se hizo evidente: el imam estaba a salvo por el momento pero tenía que viajar aun más, y en su viaje debía atravesar las tierras de sus enemigos, que se aprestaban ya a tenderle una emboscada. Al oírles gruñir y proclamar a gritos sus maléficas intenciones, el miedo y el desánimo atenazaron al pueblo.

Por supuesto, todo el mundo sabía que el imam realizaría el viaje y que lo matarían, pero al principio parecía como sí, de algún modo, ese día podía escapar a su destino(Brook, 1993, pp. 50-53).

Lo que nos narra Peter Brook de este espectáculo es que

La descarga de energía era tan intensa que no pudimos romper el circuito, y así nos encontramos en la privilegiada posición de unos observadores en el corazón de un acontecimiento de una cultura ajena, sin provocar trastorno ni distorsión alguna. El círculo funcionaba según unas leyes fundamentales y se estaba produciendo un auténtico fenómeno, el de la "representación teatral". Un suceso de un pasado muy lejano estaba siendo "representado", se estaba convirtiendo en presente; el pasado 
estaba ocurriendo allí y en ese momento, la decisión del héroe se producía entonces, igual que su angustia y las lágrimas del público existían en ese mismo instante. No se estaba describiendo o ilustrando el pasado, se había abolido el tiempo. La aldea participaba directa y completamente, allí y entonces, en la muerte real de una figura real que había muerto unos mil años antes. Les habían leído la historia muchas veces, describiéndola con palabras, pero en la forma teatral se producía la hazaña de convertirla en parte de una experiencia vivida. (Brook, 1993, p. 54)

\section{CONCLUSIÓN}

Si comparamos el antiguo teatro originario del Perú y lo que hemos podido saber acerca de las raíces del teatro griego y del teatro tal como se representa en la mayoría de países de Oriente, como el ejemplo que acabamos de citar en Irán, podríamos afirmar que más allá de las singularidades de cada uno, hay una esencia que les es común: la presencia del imaginario colectivo, que es ese "eco interior" que viene del pasado y que se hace presencia y es inmanente en estas formas de teatro, que no son las que caracterizan al teatro Occidental.

Lo característico del rito es ubicar en el aquí y el ahora un acontecimiento del pasado remoto que guarda el imaginario colectivo.

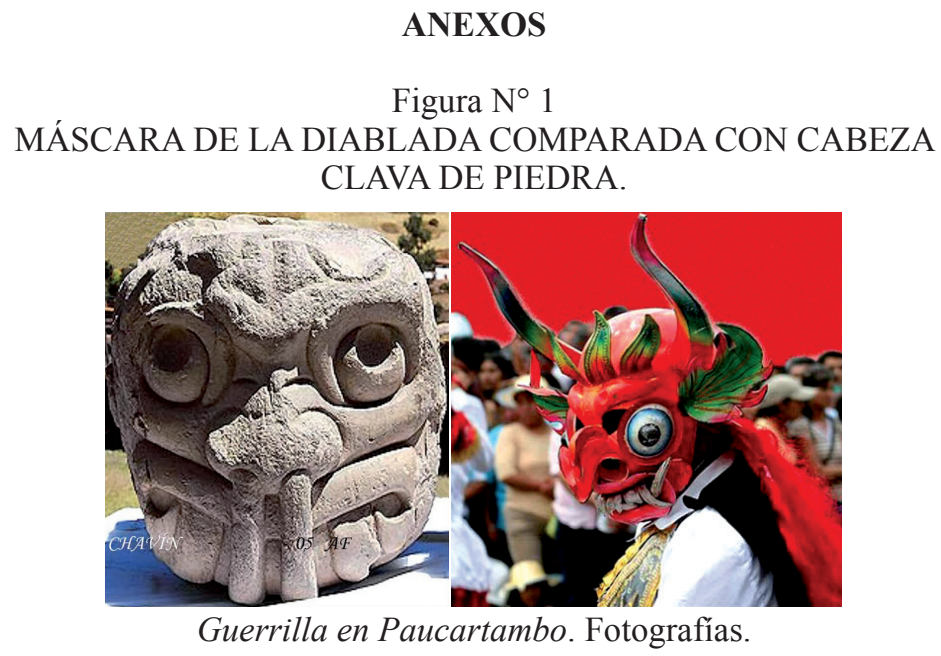


Figura $\mathrm{N}^{\circ} 2$

GUERRILLA EN PAUCARTAMBO.
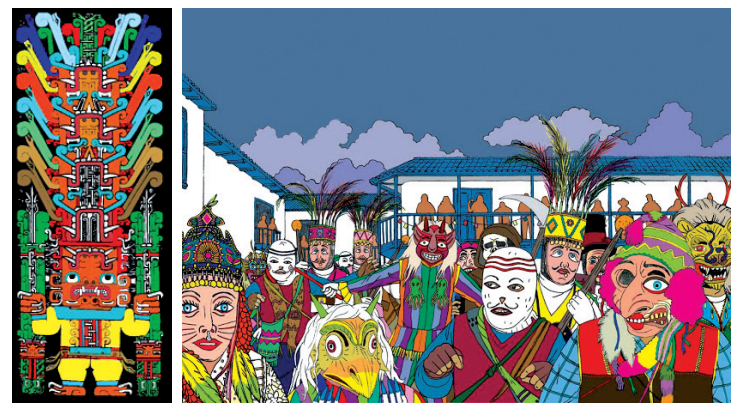

Guerrilla en Paucartambo. Ilustración: Jesús Cossio Guevara.

Figura $\mathrm{N}^{\circ} 3$

REPRESENTACIÓN DE GUERRILLA EN PAUCARTAMBO.

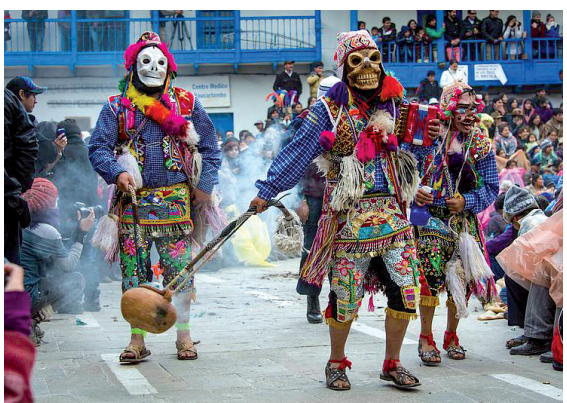

Fotografia de la Fiesta de la Mamacha Carmen (Virgen del Carmen). 
Figura $\mathrm{N}^{\circ} 4$

LOS MUSICOS AMBULANTES

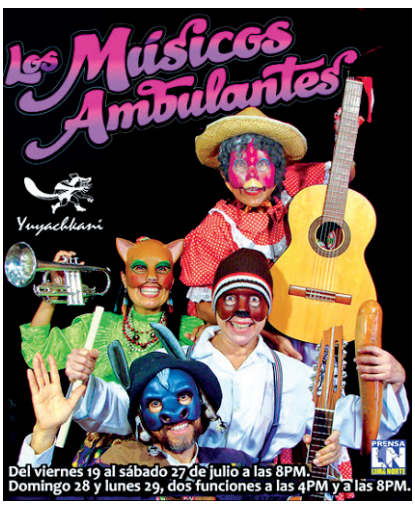

Figura $\mathrm{N}^{\circ} 5$

AFICHES DEL TEATRO YUYACHKANI

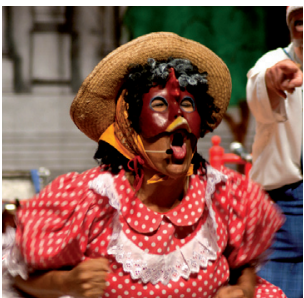

La Gallina: Sur de la Costa

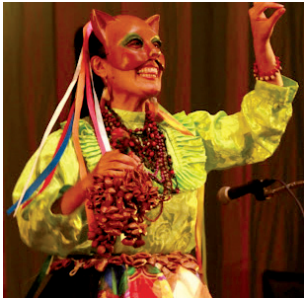

La Gata: Selva

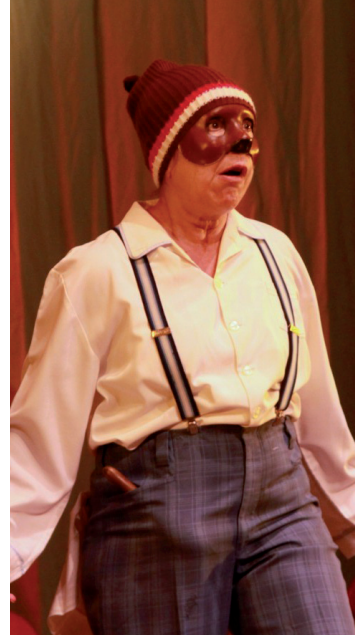

El Perro: Norte

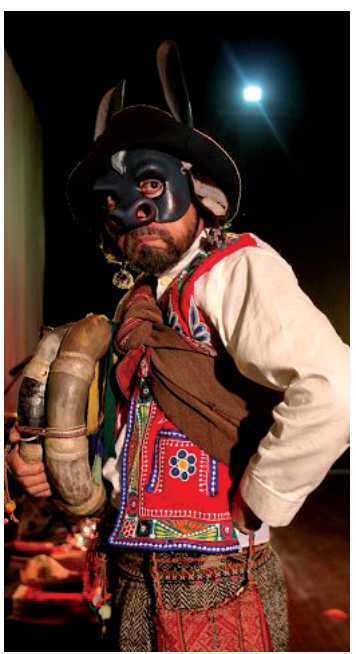

El burro: Sur Andino

Fotografías de afiches expuestos en el teatro Yuyachkani. 


\section{REFERENCIAS BIBLIOGRÁFICAS}

ARTAUD, Antonin.

2005 El teatro y su doble. $5^{\text {a }}$. ed. Buenos Aires: Sudamericana,

BARBA, Eugenio y Nicola SAVARESE

2012 El arte secreto del autor. Diccionario de Antropología Teatral. Bilbao: Artezblai.

BROOK, Peter

1993 La Puerta Abierta. Reflexiones sobre la interpretación y el teatro. Barcelona: Alba.

D'AMICO, Silvio

1954 Historia del Teatro Universal. Buenos Aires: Losada.

FOIX, Marita.

2008 Peter Brook. Teatro sagrado Teatro inmediato, Buenos Aires: Atuel.

RUBIO ZAPATA, Miguel.

2011 Raíces y semillas. Maestros y Caminos del teatro en América Latina. Lima: Grupo Cultural Yuyachkani.

2013 Guerrilla en Paucartambo. Lima: Luis Rodríguez Pastor. 